\title{
Desafios na Formação Médica: a Contribuição da Avaliação
}

\author{
Chalenges in Medical Education: the \\ Contribuition of the Evaluation
}

Luzmarina Aparecida Doretto Braccialli Maria Amélia Campos de OliveiraII

\author{
PALAVRAS-CHAVE: \\ - Educação Médica; \\ - Ensino; \\ - Avaliação da aprendizagem; \\ - Currículo; \\ - Medicina.
}

\section{KEYWORDS:}

- Medical Education;

- Teaching;

- Learning Evaluation;

- Curriculum

- Medicine.

Recebido em: 07/08/2011

Aprovado em: 21/05/2012

REVISTA BRASILEIRA DE EDUCAÇ̄̃o MÉDICA 28036 (2): $280-268 ; 2012$

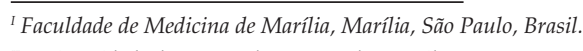

"Iniversidade de São Paulo, São Paulo, Brasil.

\section{RESUMO:}

O curso de medicina da Faculdade de Medicina de Marília (Famema) adota um currículo integrado, orientado por competência, em que a avaliação do desempenho dos estudantes recai sobre aspectos cognitivos, habilidades e atitudes. Desse modo, o objetivo deste estudo foi analisar as concepções dos professores dessa Instituição a respeito da avaliação. Para tanto, realizou-se a filmagem de 12 Exercícios de Avaliação da Prática Profissional (Eapp). Para a análise dos discursos, utilizou-se o método de interpretação dos sentidos, que se baseia em princípios hermenêutico-dialéticos. Foram identificadas diferentes concepções de avaliação, desde a mais tradicional até a mais crítica e reflexiva. Concluiu-se que o Eapp é um espaço privilegiado para avaliar o desempenho dos estudantes e problematizar a prática avaliativa dos professores.

\section{ABSTRACT:}

Introduction: the medical course at the Medical School of Marilia (Famema) has an integrated curriculum, organized by competence, in which the evaluation is based on cognitive aspects, skills and attitudes. Objective: to identify and analyze the evaluation concept of the teachers at Famema by means of the students' performance evaluation. Methodology: twelve Professional Practice Evaluation Exercises (PPEE) were filmed and recorded. The discourse analysis used the Interpretation of Meanings Method, based on dialectic-hermeneutic principles. Results: different evaluation concepts in a competence orientated curriculum were identified, the most traditional and the most critical, reflexive and negotiated ones. Conclusions: the PPEE is a privileged opportunity that allows the reconstruction of the professional practice and the teaching-learning process with special attention given to evaluation. 


\section{INTRODUÇÃO}

Na América Latina, a partir dos anos 1970, intensificou-se o debate sobre a formação médica; e tanto as estruturas curriculares como o processo de ensino passaram a ser problematizados. Projetos de integração docente-assistencial (IDA) tiveram o propósito de inserir o estudante de medicina nos vários níveis de atenção dos serviços de saúde, ampliando as oportunidades de aprendizado, antes restrito aos hospitais universitários, o que limitava o aprendizado a situações envolvendo patologias de alta complexidade. Essas experiências não foram suficientes para produzir novas relações entre universidades e serviços de saúde.

Ainda hoje se observa o predomínio do modelo clínico individual, oriundo do paradigma curricular flexneriano, na formação dos profissionais de saúde, embora tal modelo venha se mostrando insuficiente para responder à complexidade do processo saúde-doença e do paradigma curricular da integralidade do cuidado ${ }^{1 .}$

Com a implantação do Sistema Único de Saúde (SUS), estratégias para reconfigurar o modelo assistencial em saúde, entre elas a Estratégia Saúde da Família, têm sido implementadas, e as instituições de ensino vêm sendo instadas a contribuir para a formação de médicos generalistas.

Progressivamente, os movimentos de mudança na formação passam a se articular com as estratégias de reorganização das práticas de saúde, o que tem levado à construção de novos paradigmas de educação e saúde, expressos em modelos pedagógicos e assistenciais que buscam se aproximar das necessidades de saúde da população.

A educação médica no País vem sendo longamente discutida pela Associação Brasileira de Educação Médica (Abem), a Comissão Interinstitucional Nacional de Avaliação do Ensino Médico (Cinaem) e por outras instâncias que sinalizam a necessidade de mudanças na formação.

Essas discussões enfatizam a necessidade do ensino médico ocorrer em outros cenários além do hospital universitário e da formação profissional assumir um perfil mais generalista, voltado para a assistência integral, humanizada e para o trabalho em equipe. O profissional médico deve ser formado para tomar decisões "considerando não somente a situação clínica individual, mas o contexto em que vivem os pacientes"2 (p. 1).

Movimentos para a mudança na formação de recursos humanos em saúde foram impulsionados pela Lei de Diretrizes e Bases da Educação (LDB) e pelas Diretrizes Curriculares Nacionais (DCNs), que reforçam a premissa de que a formação acadêmica deve se articular com o mundo do trabalho e com as necessidades concretas das coletividades. Essas mudanças têm permitido acumular forças e conhecimentos para avançar rumo a uma formação comprometida com os princípios do SUS.

\section{O ENSINO MÉDICO NA FAMEMA}

Nos seus 45 anos de existência, a Faculdade de Medicina de Marília (Famema) tem buscado promover mudanças no ensino, visando ao aperfeiçoamento da assistência à saúde. A discussão sobre a formação do profissional médico na Famema intensificou-se com o projeto UNI - Uma Nova Iniciativa na formação dos profissionais da saúde: união com a comunidade. Esses projetos incentivaram mudanças na formação, a partir de modelos inovadores de ensino e assistência, fundamentados na integração entre ensino, serviço e comunidade e no trabalho multiprofissional e interdisciplinar, de base clínico-epidemiológica.

O acúmulo de conhecimentos decorrentes da implantação do projeto UNI na Famema permitiu a elaboração de um novo projeto educacional para a Instituição, que desencadeou uma reforma curricular significativa no curso de medicina, com a introdução de metodologias ativas de ensino. Indo ao encontro desse movimento, as Diretrizes Curriculares Nacionais (DCNs) para os cursos de medicina reforçam o processo de reformulação curricular da Famema, ampliando os espaços de reflexão e deliberação coletivas sobre os rumos educacionais, expressos na missão institucional.

Já em 1997, a Famema adotou o currículo integrado, com base em problemas e organizado por sistemas, superando a estruturação curricular dividida em ciclo básico e clínico. Desde então, os estudantes são inseridos na rede de serviços de saúde desde o $1^{\circ}$ ano, por meio de Unidade de Interação Comunitária, que tem caráter transversal, ou seja, que atravessa todas as séries.

A partir de 2003, o currículo do curso de medicina da Famema passou a ser orientado por competência, organizado em Unidades de Prática Profissional, em que os estudantes são inseridos em campos práticos de atuação. Essa mudança curricular prevê a inserção precoce dos estudantes de medicina nos serviços de saúde municipais e nas coletividades, juntamente com estudantes de enfermagem, o que permite pensar e fazer a educação dos profissionais da saúde de maneira mais contextualizada, reestruturando e transformando o modelo político-pedagógico do curso. A proposta vem sendo sustentada política e financeiramente pelos programas do Ministério da Saúde, como o Programa de Incentivo às Mudanças Curriculares nos Cursos de Medicina (Promed), de 2003, e do Pró-Saúde, de 2005.

No atual currículo do curso de medicina da Famema, o estudante é considerado sujeito da própria aprendizagem, e o professor atua como facilitador e mediador de todo o processo. A aprendizagem tem como princípios metodológicos a ação-reflexão-ação e o uso de estratégias didáticas voltadas à resolução de situações-problema. $\mathrm{O}$ referencial pedagógico 
está orientado para promover a articulação do ensino com os serviços de saúde e as coletividades, em uma perspectiva de transformação dos sistemas de saúde, da educação e da sociedade, repercutindo na formação dos profissionais da saúde.

Para avaliação, em cada uma das séries do curso, são definidas as tarefas e os desempenhos esperados. Trata-se de uma avaliação pautada em critérios, em que um padrão considerado apropriado pelos professores é utilizado para aferir o desempenho de cada estudante ao longo do curso, de modo a permitir a reorientação da aprendizagem daqueles com desempenho insatisfatório. Espera-se que esses desempenhos, demonstrados por meio de tarefas, sejam atingidos em um grau crescente, de acordo a apropriação do estudante.

As avaliações de processo são contínuas e sistemáticas e servem para monitorar o desenvolvimento individual e planejar atividades educativas adaptadas às necessidades de cada estudante. As atividades são realizadas em campo, nas Unidades de Saúde da Família e nas Unidades Hospitalares, em conjunto com a Unidade Educacional Sistematizada (UES) e o Laboratório de Prática Profissional (LPP).

No LPP, as atividades são previamente estruturadas pelos professores na forma de situações simuladas, muito próximas das vivenciadas pelos estudantes nos campos de prática. Para representar pacientes, são contratados atores, que atuam em situações planejadas as quais permitem ao estudante desenvolver suas habilidades sem o receio de cometer os erros inerentes ao processo de aprendizagem.

As situações simuladas são realizadas no LPP no decorrer do ano e funcionam como estratégias para o processo de ensino-aprendizagem. Ao término do ano letivo, estudantes de todas as séries passam por um momento formal de avaliação denominado Exercício de Avaliação da Prática Profissional (Eapp). Em todas as séries do curso, essa avaliação tem caráter diagnóstico, formativo e somativo.

\section{A AVALIAÇÃO NO CAMPO DA EDUCAÇÃO MÉDICA}

O reconhecimento progressivo da importância da avaliação tem propiciado seu grande desenvolvimento no campo da educação médica. Essa evolução resulta em uma diversidade de conceitos e métodos aplicáveis a situações específicas, bem como no aumento da complexidade e da dificuldade inerente à prática avaliativa.

A avaliação do estudante de medicina é um processo de coleta de informações, realizado por meio de atividades sistemáticas e formais, que permite saber o que o estudante conhece, sabe fazer e se o faz de modo adequado, corrigindo distorções e reforçando aspectos positivos. Contempla não só o conhecimento adquirido, mas também habilidades específicas e elementos de ordem afetiva, como as atitudes diante de inúmeros aspectos da prática profissional ${ }^{3}$.

O descontentamento com os métodos tradicionais de avaliação de habilidades clínicas e o desenvolvimento nos campos da psicologia e da educação levou ao desenvolvimento da modalidade denominada avaliação de desempenho ${ }^{4}$.

A avaliação com pacientes simulados é uma modalidade não tradicional de avaliação de desempenho que permite simular situações com as quais todos os estudantes podem entrar em contato. Os professores selecionam situações que consideram importantes para a formação e que nem sempre os estudantes têm a oportunidade de vivenciar na prática ${ }^{5}$.

Na Famema, as situações simuladas são utilizadas durante todo o processo de ensino-aprendizagem e também nos momentos formais de avaliação, tendo como propósito criar condições mais favoráveis para aprender sem prejuízo aos usuários.

O uso de situações simuladas no curso de graduação em medicina da Famema teve início em 1997, quando foi realizada a primeira reforma curricular e passou-se a utilizar o $\mathrm{Ob}$ jective Structured Clinical Examination (Osce) para avaliação de habilidades clínicas dos estudantes.

Atualmente, a avaliação com pacientes simulados continua a ser utilizada no Eapp, que tem como foco a integralidade do cuidado. Para ser colocada em prática, essa modalidade de avaliação exige grande empenho e investimento institucional na capacitação de professores ${ }^{5}$.

A avaliação do desempenho dos estudantes no Eapp envolve entrevista e exame clínico, formulação do problema, elaboração e execução do plano de cuidados. O estudante dispõe de 50 minutos para realizar as ações propostas e outros 10 minutos para a avaliação, que inclui a autoavaliação do estudante e a devolutiva dos avaliadores.

Avaliações de desempenho em situações simuladas, ou em condições reais do mundo do trabalho, permitem avaliar a capacidade do estudante de combinar recursos no momento da ação. Esse tipo de avaliação tem alto grau de realismo e permite fazer inferências sobre a competência futura do estudante no exercício profissional ${ }^{6}$.

\section{OS SENTIDOS DA AVALIAÇÃO}

Avaliação é uma prática social, intersubjetiva e permeada de valores, que articula processos globais da sociedade e aspectos relacionados à educação, tais como os sentidos atribuídos ao conhecimento, aos aspectos morais e à vida pública e social. Seu propósito é construir campos sociais de discussão, valorizar tanto o produto como o processo nas atividades educati- 
vas, com o propósito de uma promover uma sociedade mais democrática e justa ${ }^{7}$.

A avaliação deve ser entendida como um bem público, um processo dinâmico de construções democráticas, autônomas, com responsabilidade social, para a formação de pessoas com autonomia e ética e o enriquecimento do conhecimento científico ${ }^{8}$.

Entretanto, a avaliação também é um campo de disputa por práticas sociais de distintos lugares acadêmicos, políticos e sociais, um campo complexo, plurirreferencial e polissêmico, com referenciais múltiplos e heterogêneos ${ }^{9}$. Atualmente, é entendida como um instrumento de poder ligado a todos os domínios sociais, principalmente à estruturação e à gestão dos setores educacionais.

A avaliação educacional permite a reflexão sobre determinantes sociais da aprendizagem e exerce papel fundamental na escola, no currículo e em seus programas. Possibilita monitorar o processo de ensino e aprendizagem e analisar suas causas e consequências, o que contribui para a tomada de decisões nesse campo, sendo realizada sem interrupções por estudantes, pacientes simulados e professores.

$\mathrm{Na}$ proposta curricular do curso de medicina da Famema, a prática avaliativa busca promover o diálogo entre as funções técnicas, éticas e políticas da formação, com vistas a superar as dicotomias objetivo/subjetivo, produto/processo, hetero/autoavaliação, formativo/somativo, fragmentação/ integração ${ }^{10}$.

Para tanto, não basta só mudar as metodologias de ensino, mas é fundamental e necessária uma nova prática do professor. Nesse novo processo avaliativo, o professor deixa de ser fiscalizador, medidor e julgador, para ser o mediador do processo de ensino-aprendizagem. Isso requer alteração da concepção pedagógica e introdução de novas formas de ensinar e de avaliar, incentivando a prática reflexiva e ressignificando o conhecimento.

O que reafirma uma formação profissional crítica e progressista ou tecnicista e conservadora é o modo de entender e fazer educação, o modo como são trabalhadas em sala de aula as estratégias de aprendizagem utilizadas, o uso que se faz da avaliação e a relação existente entre professor e estudante ${ }^{11}$.

No caso da Famema, a adoção de um currículo integrado, orientado por competência, trouxe consigo a necessidade de uma visão crítica e reflexiva, mediante a qual o trabalho pedagógico busca aproximar o pensamento e a ação.

O presente estudo tem como objetivo identificar e analisar a concepção de avaliação dos professores da Famema por meio da análise do Eapp, com vistas a subsidiar seu aperfeiçoamento.

\section{MÉTODO}

Realizou-se uma pesquisa qualitativa que permitiu refletir sobre o processo de ensino e aprendizagem, em especial o momento avaliativo na educação médica na Famema ${ }^{12}$. Para registrar o desempenho do estudante em sua interação com o paciente simulado, assim como a avaliação subsequente dos professores, foi realizada a filmagem de 12 Eapp. O material resultante foi transcrito, resultando em textos que foram submetidos à análise de acordo com o método de interpretação dos sentidos ${ }^{13,14}$.

O grupo estudado foi composto por professores e estudantes do curso de Medicina da Famema. Foram filmadas duas situações simuladas na $1^{\underline{a}}$ série; três na $3^{\text {a }}$; três na $4^{\text {a }}$; e quatro na $6^{\underline{a}}$ série. A coleta de dados foi realizada de novembro de 2007 a maio de 2008. A análise do material teve início com a leitura em profundidade de cada texto, visando à apreensão dos sentidos, como preconiza o método de interpretação de sentidos ${ }^{13,14}$, que busca interpretar o contexto, as razões e as lógicas de falas, as ações e as inter-relações entre os grupos envolvidos. Trata-se de um método hermenêutico-dialético, pois procura realizar "uma reflexão densa acerca do diálogo entre hermenêutica (compreensão) e dialética (crítica) e traz princípios que podem servir de baliza para a operacionalização do método de interpretação dos sentidos ${ }^{\prime 12,14}$ (p. 99). A pesquisa teve a aprovação do Comitê de Ética em Pesquisa da Famema, protocolo no 594/07.

\section{RESULTADOS}

Treze professores participaram do estudo, sete $(53,8 \%)$ do sexo masculino e seis $(46,2 \%)$ do feminino, com idades que variaram de 31 a 58 anos e mediana de 52 anos. Quanto à formação em nível de pós-graduação, constatou-se a presença de três $(23,0 \%)$ especialistas, quatro $(30,8 \%)$ mestres e seis $(46,2 \%)$ doutores. A formação especializada concentrou-se nas áreas de pediatria $(30,8 \%)$, cirurgia geral $(23,0 \%)$, psiquiatria $(15,4 \%)$, parasitologia $(7,7 \%)$, ginecologia e obstetrícia $(7,7 \%)$, enfermagem clínica $(7,7 \%)$ e enfermagem pediátrica $(7,7 \%)$.

Os professores atuavam em unidades hospitalares $(46,2 \%)$, ambulatórios de especialidades $(23,0 \%)$, unidades da Estratégia Saúde da Família (23,0\%) e laboratório (7,7\%). O tempo de atuação nas referidas áreas variou de 1 a 32 anos, sendo que para a maioria $(60,0 \%)$ ultrapassou 12 anos.

O tempo despendido nos Eapp variou de 17 a 91 minutos nas diferentes séries, com mediana de 49 minutos, incluindo o desempenho do estudante e a avaliação realizada por professores e estudantes. O menor tempo utilizado pelos estudantes para a realização das tarefas propostas foi de 14 minutos e o maior, de 61, com mediana de 42 minutos. A devolutiva do 
professor levou o menor tempo, de 3 a 23 minutos, com mediana de 6,5 minutos.

\section{OS SENTIDOS DA AVALIAÇÃO E SEUS PRINCÍPIOS EXPRESSOS NO EAPP}

A forma como os professores realizam o momento avaliativo durante o Eapp permite expressar os sentidos que atribuem ao processo de ensino-aprendizagem e, em especial, à avaliação. Por ser uma ação prática, o Eapp propicia "olhar por dentro" do processo de avaliação e constatar diferentes concepções de competência vinculadas a referenciais teóricos distintos, principalmente os modelos de base comportamental e os construtivistas, resultados das inúmeras mudanças do conceito de competência ao longo dos anos.

Essas mudanças vão desde o referencial comportamental utilizado na formação de profissionais técnicos, com ênfase na realização de tarefas, até uma abordagem construtivista sociocultural, em que as ações articulam-se e integram-se com recursos cognitivos, afetivos, psicomotores, em diferentes contextos, nos quais as ações têm grande importância em relação às ideias de memorização compreensiva, funcionalidade do conhecimento e aprendizagem significativa ${ }^{15}$.

A matriz de competência de base comportamental, entendida como a necessidade de expressar claramente os objetivos de ensino em termos de condutas e práticas observáveis, pode ser ilustrada quando o professor, ao discutir o desempenho do estudante no processo avaliativo, enumerou as tarefas realizadas e as que ele deveria "saber fazer"15.

— Então, você identificou a parada, realizou a estabilização, executou o choque e a conduta apropriada, reconheceu a necessidade de adrenalina, lidocaína, vasodilatadores. As consequências do choque você teve dificuldade de identificar. A sondagem você não fez e está diretamente relacionada ao trauma. (P9)

Em outra situação, para evidenciar as fragilidades do estudante na realização do exame físico, o professor realizou uma demonstração no momento final da avaliação. Após o término da atividade realizada pelo estudante, pediu ao paciente que se deitasse novamente, dizendo para o estudante: "Você está de parabéns! Mas só precisa prestar atenção numa coisa [...]" (P6). Em seguida, demonstrou a verificação dos sinais em que o estudante teve dificuldade, explicando cada passo detalhadamente. Realizou as manobras enquanto o estudante, ao seu lado, prestava atenção. Solicitou então que repetisse os procedimentos demonstrados.

Em ambas as situações, os professores adotaram uma postura que privilegia a execução de um conjunto de tarefas, como em um check list, e a avaliação têm caráter de medida, incidindo sobre os resultados, que devem expressar eficiência. As referidas situações teriam propiciado a estudantes e professores momentos privilegiados de aprendizagem se tivessem sido contextualizadas e não somente focalizadas no procedimento.

Os professores poderiam tê-las problematizado, levando os estudantes a reconhecerem os limites e as potencialidades que apresentavam, assim como suas deficiências de aprendizagem. Poderiam até mesmo elaborar questões de aprendizagem que motivassem os estudantes a buscar diversas fontes e, em um momento posterior, discutir com eles próprios ou com outros professores, até mesmo sob a forma de consultoria, de modo a refletirem conceitos e condutas adotadas.

No referencial comportamentalista, o processo de ensino-aprendizagem e a avaliação focalizam resultados e produtos, em detrimento do processo e dos atributos que fundamentam as práticas; tem uma relação direta com as ações. Nessa avaliação, professores e estudantes ocupam espaços distintos e antagônicos. O currículo, por sua vez, está estruturado para possibilitar o desempenho de funções e ações, e a aprendizagem fica restrita às atividades.

Essa matriz de competência foi identificada nas situações simuladas, como: no diagnóstico médico, no tratamento e no prognóstico do paciente simulado. Na devolutiva, alguns professores demonstram valorizar mais o produto que o processo. Iniciaram a avaliação questionando o estudante sobre quais exames laboratoriais solicitaria. Inquiriram-no ainda sobre o diagnóstico e o prognóstico para o caso. Não deram retorno ao estudante, não abriram espaço para discussão de seu desempenho, restringindo-se a discutir o diagnóstico no caso.

- Normalmente, as doenças dos casos que eu vi assim não têm muita terapêutica, o fato sugere, mas não dá para descartar uma anemia e um quadro depressivo. (E5)

- Não fica um quadro depressivo. (P5)

Em outro caso, na área Saúde do Adulto, o estudante ia verificar os sinais vitais e o professor interferiu, dizendo que não era necessário: "Não precisa não, faz de conta que você verificou [...]" (P5). Igualmente preocupado com o produto, o professor não valorizou a tarefa que o estudante realizaria para atingir o desempenho esperado para aquele momento. A intervenção limitou-se a encaminhamentos e orientações.

Trata-se de uma tendência de avaliação que focaliza a combinação de atributos a serem mobilizados nas ações executadas, sob a forma de capacidades cognitivas, psicomotoras e afetivas. Em consequência, a avaliação centra-se na verifica- 
ção dos atributos enquanto função e resultados. O referencial pedagógico adotado é o humanista, porém o contexto social é pouco valorizado. Estão presentes atributos fortemente vinculados ao conhecimento (saber), resultado da crença de que quem sabe é capaz de fazer ${ }^{15,16}$.

Outro exemplo dessa tendência foi o caso em que o professor trabalhou com a estudante a interação e o vínculo durante um atendimento que envolveu mãe e criança. Explorou a história clínica, o exame físico e laboratorial, o diagnóstico médico, a conduta para o caso, o prognóstico, os protocolos de conduta e o preparo do ambiente. Além das condutas referentes ao caso, destacou as medidas de biossegurança e o controle de infecção hospitalar: "Você fez uma coisa legal que eu vejo que o pessoal não tem feito: lavar as mãos [...] a gente tem normas de controle de infecção [...] Não pode usar relógio, brinco grande [...] tem de lembrar" (P10).

A outra professora presente à avaliação, no momento da devolutiva ao estudante, reforçou que a situação envolvia dimensões sociais, biológicas e psicológicas, enfatizando que esse último aspecto não havia sido explorado.

Outro ponto relevante é a comparação dos desempenhos dos diferentes estudantes. Há professores com dificuldade para entender que, em um currículo integrado e orientado por competência, a avaliação é critério-referenciada, de tal modo que a comparação entre desempenhos só faz sentido quando referida aos desempenhos do próprio estudante em momentos anteriores. A avaliação comparativa entre os estudantes só reforça os princípios da avaliação tradicional, na qual predomina a classificação e a competição.

Também foi possível identificar a dificuldade do professor para atribuir o conceito final. Como na avaliação praticada na Famema não existe a "dependência", o desempenho do estudante é considerado satisfatório ou insatisfatório. Nesse último caso, o estudante necessita passar por um período de recuperação até atingir o desempenho proposto para a série. Os professores, em diferentes momentos, deparam-se com a necessidade de critérios claramente definidos para serem aplicados com objetividade no Eapp.

Nas séries em que a avaliação do Eapp não tem caráter somativo, os professores encontram mais facilidade para justificar um conceito final satisfatório, destacando algo que ainda precisa ser aprofundado, do que um conceito insatisfatório. "No exame físico, requer um melhor aprofundamento do exame de pele [...] Detalhar, para não ficar um ar de que está insatisfatório [sic] [...] Porque ela deu uma olhada na pele [sic]..." (P1).

Em um Eapp de caráter somativo, realizado na $4^{\underline{a}}$ série, o desempenho claramente insatisfatório de uma estudante foi avaliado como satisfatório, o que vem confirmar a disparidade de critérios entre os professores nos diferentes momentos do processo avaliativo.

\section{- [...] o mais adequado é você acompanhar o paciente, tratar os sintomas, acompanhar, orientar, do que você entrar precocemente, desnecessário [sic], com o antibi- ótico. (P7) \\ - Sei que não é para medicar, mas como o senhor falou da receita [...]. (E6) \\ —Aí você sentiu que tinha que medicar?. (P7)}

No caso acima, o professor registrou no instrumento de avaliação o conceito insatisfatório (I) no plano de cuidados, porém atribuiu o conceito satisfatório (S) no final, recomendando ao estudante melhorar a parte da história clínica e a avaliação global da criança e do plano terapêutico. Outro professor ficou indeciso quando registrou no instrumento o conceito final do estudante: "Fiquei muito em dúvida sobre o S..." (P1).

$\mathrm{Na}$ maioria desses casos, os professores demonstraram dificuldade para atribuir um conceito insatisfatório ao desempenho do estudante "pela subjetividade do referente, a integralidade do objeto, pelas atividades e pelos instrumentos de avaliação"17 (p. 5), o que reforça o sentido da avaliação tradicional e de competência com base na matriz comportamental.

Entretanto, também foi possível constatar sentidos da avaliação vinculados à matriz construtivista sociocultural, que guarda maior aproximação com a escola crítica. Nesta, parte-se de um contexto social em busca de fundamentação teórico-prática, para transformá-lo em um movimento de ação-reflexão-ação em situação prática do mundo do trabalho. O desempenho (capacidades em ação) e os padrões de competência são utilizados como dimensões da avaliação. Busca-se a integração entre teoria e prática, considerando o contexto, a cultura do local de trabalho, os valores, a política e a ética ${ }^{15,16}$.

Nessa concepção, a competência expressa "uma síntese do perfil profissional ou um julgamento atribuído a alguém em relação à avaliação de sua prática profissional", segundo contexto e padrões de excelência ${ }^{18}$ (p.125).

O currículo por competência busca a integrar os conhecimentos gerais, profissionais e a experiência no trabalho, proporcionando a interação entre conhecimentos, habilidades e atitudes em um dado contexto social, a realidade local. $\mathrm{O}$ desempenho é considerado de forma mais abrangente, com seus valores éticos, políticos e culturais.

Esse modelo de competência, que consiste em uma abordagem integral, precisa ser construído no diálogo entre a for- 
mação e o mundo do trabalho, no qual se desenvolvem as práticas profissionais. Requer um processo ativo de ensino e aprendizagem, com uso de metodologias ativas, com um ensino que dê significado aos conhecimentos, articulando-os aos problemas reais do mundo do trabalho ${ }^{15,16}$.

A formação é orientada pelo trabalho, de modo a contribuir para a superação das práticas em saúde vigentes, por meio da ação reflexiva. O diálogo entre formação e trabalho propicia ao estudante mobilizar recursos para construir seu desempenho na ação, de forma pertinente e no momento oportuno, para solucionar problemas e necessidades de saúde encontradas nos campos de prática. O processo de avaliação é dialógico e necessita da participação de todos os sujeitos envolvidos. Valoriza o processo tanto quanto o resultado, e possibilita a verificação das aprendizagens articuladas e integradas em situações reais e simuladas.

Foi possível identificar a presença da concepção construtivista de avaliação no Eapp quando um professor valorizou a integralidade do atendimento, dando destaque à combinação de atributos (conhecimentos, valores, atitudes e habilidades), considerou o contexto social do paciente, seu grau de autonomia, a relação médico-paciente, o estabelecimento de vínculos, a comunicação verbal e não verbal. No plano de cuidados, valorizou não apenas a dimensão biológica, mas também a psicológica, a social e a cultural, assim como o envolvimento da equipe multiprofissional nas ações de promoção, prevenção, tratamento e reabilitação, nos diferentes níveis de atendimento.

\footnotetext{
- Acho que, no final, você já apontou a questão da segurança para tentar conduzir [sic] e envolvê-la [sic] na questão da decisão que ela está tomando, para que ela pudesse participar mais, você pode estimular isso. Contar com a equipe, em termos de promoção e prevenção da saúde, pode abordar alguma coisa [sic]. (P10)
}

A avaliação ocorre por meio do diálogo, e os professores sugerem como desenvolver um plano de cuidados para a situação vivenciada. Juntamente com o estudante, desenvolvem uma avaliação com base na problematização, ambas as partes argumentando e discutindo.

Uma professora proporcionou ao estudante a oportunidade para pensar e refletir antes de responder. Questionou o porquê de ter realizado determinado procedimento de uma forma e não de outra, aguardando uma justificativa fundamentada em princípios científicos.

Ao avaliar um estudante, outro professor considera que "ele faz um trabalho amplo, explora bem, tem contato bom. Tem alguns probleminhas, que são típicos de uma situação como esta, e é importante que a gente assinale [...] uma coisa que pode ser corrigida com o tempo" (P1).

Ao agir assim, os professores revelaram que compreendem a aprendizagem como um processo. Sabem que o estudante não precisa estar "pronto" no momento da avaliação. Em seus comentários, alertaram o estudante para "estar atento ao tempo que tem para realizar os cuidados e assim priorizar elementos para aquele contato" (P1).

Atitudes de professores comprometidos com a formação do estudante anunciam a ressignificação das competências, instigando os estudantes a desenvolverem "competências socialmente pertinentes, colocando, sob suspeição, as competências regidas pelo viés mercadológico"19 (p. 93).

Porém, houve quem esperasse que o estudante chegasse à avaliação sabendo tudo e aproveitasse o momento do Eapp para estimulá-lo a estudar nas férias, para se preparar mais para a série seguinte. Justificou sua postura dizendo que, embora algumas partes do exame físico não tivessem sido exploradas no dia a dia, o estudante conseguiu realizá-las no Eapp porque conseguiu treinar antes: "Mas a gente pode colocar como dependência (DP) alguns detalhes [...]. "A gente coloca [que] ele é um estudante satisfatório pelo que a gente percebe, mas [...]" (P2).

Embora na 1aㅗ série a avaliação do Eapp tenha caráter essencialmente formativo, percebe-se a preocupação do professor de não deixar que o estudante saia com deficiências em algum desempenho esperado para esse momento. Também se percebe que o professor sente-se avaliado pelos seus pares, de tal forma que acaba realizando "treinamentos" com seus estudantes. O Eapp é um momento de exposição do professor, que tem a preocupação com o que pensam os demais docentes e também com o fato de que irá reencontrar o estudante nas séries subsequentes.

Houve ainda um professor que alertou o estudante para o custo-benefício das ações do profissional e apontou o seu descrédito no Sistema Único de Saúde.

- Eu garanto para você que não tem, pelo SUS, não. Mas particular está cheio. Então, imagina, ela vai ter que se deslocar nesse meio, vai retardar seu diagnóstico e ela está há seis meses sangrando de 10 a 13 dias. Então, vai raciocinando. Então, era isso, de custo e efetividade. (P11)

Outro reforçou a potencialidade do cenário real para a avaliação do processo de ensino-aprendizagem, em detrimento do cenário simulado, mesmo quando a estudante argumentou que também encontra dificuldades de aprendizagem no cenário real. 
- O que você achou de passar do ser humano para o manequim? (P13)

— Ah! Eu não acho que seja bom. (E13)

- O que você faria se fosse a realidade? (P13)

- Eu acho que acontece um viés, não sei. Com certeza seria diferente se eu tivesse feito numa paciente. (E13)

- O que você acha de passar do manequim para o ser humano? (P13)

— Eu também acho que é difícil. Acho que quando é só a paciente, você vai traçando um raciocínio diagnóstico melhor, a hipótese diagnóstica melhor. Tem de mudar muito rápido de um cenário para outro. (E13)

$\mathrm{Na}$ autoavaliação, o estresse apareceu como um determinante do desempenho do estudante. No momento de discutir a avaliação com o estudante, esse é um aspecto que os professores levam em consideração ao atribuir o conceito final, principalmente nas séries iniciais dos cursos.

Na primeira série, quando o Eapp é realizado pela primeira vez, os professores são mais compreensivos, tolerantes mesmo, por entenderem que os estudantes encontram-se em um momento inicial de aprendizagem e de avaliação, principalmente a avaliação da prática profissional, que envolve conhecimento, habilidade e postura na ação: "Você tem de se cuidar, você cuida dele [referindo-se ao paciente], mas aí você tem de cuidar de você também" (P1).

Nas séries finais do curso, entretanto, os professores esperam que o estudante esteja "pronto" e o Eapp assume caráter mais somativo. Alguns professores já não admitem erros nessa fase do processo de ensino-aprendizagem. "Jamais se examina uma paciente com a bexiga cheia [...], então, esse é um erro que normalmente se comete e você não deve mais cometer, tá bom? [...] Então, você não vai mais cometer" (P11).

Todos os professores abordaram o conjunto das tarefas propostas para as séries, identificando potencialidades e fragilidades no desempenho do estudante. Porém, a forma como interagiram com os estudantes no momento avaliativo foi muito diversificada. Alguns priorizaram somente a tarefa, sendo prescritivos e demonstrando procedimentos. Outros percorreram todas as ações esperadas, explorando cada uma delas em todas suas dimensões, questionando o estudante e utilizando a avaliação como um momento privilegiado de aprendizagem.

O estudo reafirma que professores encontram dificuldades para avaliar atitudes, têm falta de clareza sobre o que avaliar e carecem de instrumental específico para determinar do grau de aprendizado de cada estudante. A avaliação do componente atitudinal é complexa e requer consenso entre os docentes sobre quais seriam as atitudes a serem desenvolvidas no curso para, a partir disso, construir instrumentos de aprendizagem e de avaliação compatíveis com a proposta curricular. ${ }^{20}$

\section{CONCLUSÕES}

O Eapp revelou potencial para evidenciar fragilidades e potencialidades dos professores envolvidos no processo de ensino-aprendizagem, em especial no processo avaliativo, assim como constatar a diversidade e a ausência de critérios consensuados entre eles, em que pesem mais de 13 anos de implementação desse formato de avaliação na Famema.

Possibilitou ainda identificar os diferentes sentidos da avaliação presentes na prática avaliativa dos professores. A diversidade e a heterogeneidade de significados identificados no espaço da avaliação, em especial no Eapp, possivelmente se fazem presentes nos demais momentos de aprendizagem.

Ficou evidente a dificuldade de "desfazer-se do velho", ou seja, da prática avaliativa tradicional, associada à objetividade, notas ou conceitos e provas escritas. Incorporar o "novo" significa assumir uma prática avaliativa similar às situações reais encontradas na profissão, plena de subjetividade, negociada, dialógica e democrática. Uma interação de sujeitos em que todos aprendem e se comprometem com o aprendizado, sem hierarquia de poder, em que não faz sentido o julgamento, a comparação entre estudantes, "a nota", e sim o desempenho como expressão da competência esperada e do perfil profissional pretendido.

Constatou-se que os diferentes sentidos atribuídos à avaliação decorrem dos distintos enfoques de educação e de competência. Daí decorre a necessidade de repensar a prática avaliativa exercida pelos professores da Famema e reconstruí-la coletivamente, de modo coerente com o projeto pedagógico do curso e com a proposta de avaliação vinculada à matriz de competência, fundamentada na corrente pedagógica construtivista sociocultural, pois "a adesão aos métodos pedagógicos dessa linha de atuação exige uma mudança significativa na forma de conceber o ensino e a aprendizagem"21 (p.187).

A pedagogia das competências no ensino médico encontra-se hoje respaldada nas DCNs e vem sendo incentivada pelos programas ministeriais como estratégia para promover mudanças curriculares nas escolas médicas, superando o paradigma flexneriano. Este prioriza o ensino por especialidades, a visão biologicista e tecnicista, em que o professor é o centro, o aluno é mero receptor e não se responsabiliza pela construção do seu conhecimento ${ }^{21}$.

No projeto pedagógico do curso de medicina da Famema, o Eapp é um espaço privilegiado que permite a construção da prática profissional. Em que pese a diversidade de concepções de educação, competência e avaliação identificadas, é possível 
observar a criatividade, a sensibilidade e a disponibilidade de professores e estudantes na construção de um processo ativo de ensino e aprendizagem.

Para superar as concepções de avaliação mais tradicionais, focadas no produto, recomenda-se a utilização do espaço da educação permanente para os professores, de modo a favorecer o diálogo sobre o processo avaliativo, considerando a historicidade das profissões da saúde, sua inserção no mundo do trabalho e as diferentes concepções de avaliação de competência na formação inicial, com possibilidade de pensar conjuntamente a formação de futuros profissionais da saúde.

\section{REFERÊNCIAS}

1. Scherer MDA, Marino SRA, Ramos FRS. Rupturas e resoluções no modelo de atenção à saúde: reflexões sobre a Estratégia Saúde da Família com base nas categorias kuhnianas. Interface Comun Saúde Educ 2004 set-2005 fev; 9(16): 53-66.

2. Feuerwerker LCM. Além do discurso de mudança na educação médica: processos e resultados. São Paulo: Hucitec; 2002.

3. Troncon LEA. Avaliação do estudante de medicina. Medicina (Ribeirão Preto)1996; 29(4):429-39.

4. Howley LD. Performance assessment in medical education: where we've been and where we're going. Eval Health Prof 2004; 27(3): 285-303.

5. Mazzoni CJ, Moraes MAA. A avaliação prática estruturada de habilidades clínicas na Famema: fundamentos para construção e aplicação. Gestão Univ. [on-line].2006. (99) [capturado 21 maio 2007]. Disponível em: http:// www.gestaouniversitaria.com.br/edicoes/68-99/321-a-avaliacao-pratica-estruturada-de-habilidades-clinicas-na-Famema--fundamentos-para-construcao-e-aplicacao.pdf

6. Faculdade de Medicina de Marília — Famema. Manual de avaliação do estudante: cursos de medicina e enfermagem. Marília: Faculdade de Medicina de Marília; 2006.

7. Dias Sobrinho J. Avaliação: políticas educacionais e reformas de educação superior. São Paulo: Cortez; 2003.

8. Dias Sobrinho J. Avaliação educativa: produção de sentidos com valor de formação. Avaliação (Campinas) 2008;13(1):193- 207.

9. Freitas LC. Avaliação: construindo o campo e a crítica. Florianópolis: Insular; 2002.

10. Laluna MCMC. Os sentidos da avaliação na formação de enfermeiros orientada por competência. Ribeirão Preto; 2007. Doutorado [Tese] — Escola de Enfermagem de Ribeirão Preto.

11. De Sordi MRL, Bagnato MHS. Subsídios para uma formação profissional crítico-reflexiva na área da saúde: o de- safio da virada do século. Rev. Latino-Am. Enferm. 1998; 6(2):83-8.

12. Minayo MCS. O desafio do conhecimento: pesquisa qualitativa em saúde. 6a ed. São Paulo: Hucitec; 1999.

13. Gomes R, Souza ER, Minayo MCS, Malaquias JV, Silva CFR. Organização, processamento, análise e interpretação de dados: o desafio da triangulação. In: Minayo MCS, Assis SG, Souza ER, org. Avaliação por triangulação de métodos: abordagem de programas sociais. Rio de Janeiro: Editora Fiocruz; 2005. p.185-221.

14. Gomes R. Análise e interpretação de dados de pesquisa qualitativa. In: Minayo MCS, org. Pesquisa social: teoria, método e criatividade. 25a ed. Petrópolis: Vozes; 2007. p.79-108.

15. Ramos MN. A pedagogia das competências: autonomia ou adaptação? 2a ed. São Paulo: Cortez; 2002.

16. Lima VV. Competência: distintas abordagens e implicações na formação de profissionais de saúde. Interface Comun Saúde Educ 2005;9(17):369-379.

17. Laluna MCMC, Ferraz CA. Os sentidos da prática avaliativa na formação de enfermeiros. Rev. Latino-Am. Enferm. 2009;17(1):21-7.

18. Lima VV. Avaliação de competência nos cursos médicos. In: Marins JJN, Rego S, Lampert JB, Araújo JGC, orgs. Educação médica em transformação: instrumentos para a construção de novas realidades. São Paulo: Hucitec; 2004. p.123-40.

19. Sordi MRL, Silva MM. O exercício competente da docência universitária em tempos de incompetências sociais. In: Rovai E, org. Competência e competências: contribuição crítica ao debate. São Paulo: Cortez, 2010. p.92-125.

20. Nosow V, Püschel VAA. O ensino de conteúdos atitudinais na formação inicial do enfermeiro. Rev. Esc. Enferm. USP 2009; 43 (2):1232-7.

21. Carvalho Filho CJ. Entre a teoria e a prática: o projeto político-pedagógico do curso de medicina da UFMA. Marília; 2011. Tese [doutorado] — Universidade Estadual Paulista - UNESP.

\section{CONFLITO DE INTERESSE}

Declarou não haver.

\section{ENDEREÇO PARA CORRESPONDÊNCIA}

Luzmarina Braccialli

Escola de Enfermagem da Universidade de São Paulo (USP).

Av. Monte Carmelo, nํㅛ 800

Marília - SP, Brasil

CEP: 17519-030.

e-mail: luzbra@terra.com.br, luzmari@Famema.br 